\title{
FISCAL EQUALIZATION AND YARDSTICK COMPETITION
}

\author{
CHRISTOS KOTSOGIANNIS \\ ROBERT SCHWAGER
}

\author{
CESIFO WORKING PAPER NO. 1865 \\ CATEGORY 1: PUBLIC FinANCE \\ DECEMBER 2006
}

An electronic version of the paper may be downloaded

- from the SSRN website:

- from the RePEc website:

wWw.SSRN.com

- from the CESifo website:

Www.RePEc.org

www.CESifo-group.de 


\title{
FISCAL EQUALIZATION AND YARDSTICK COMPETITION
}

\begin{abstract}
A multi-jurisdictional system is thought to improve, through yardstick competition, accountability. At the same time equalization programs, a common feature of multijurisdictional systems, are thought to be a prerequisite for both efficiency of the internal market and the equity objective of the equal treatment of equals. This paper shows that such programs, by reducing the information context of comparisons across jurisdictions, introduce perverse fiscal incentives and thus reduce accountability. The consequence of this is that equilibrium rent-taking increases with the intensity of equalization transfers.
\end{abstract}

JEL Code: D72, H77.

Keywords: equalization transfer programs, fiscal capacity, rent-seeking, fiscal federalism.

\author{
Christos Kotsogiannis \\ Department of Economics \\ School of Business and Economics \\ University of Exeter \\ Streatham Court, Rennes Drive \\ Exeter EX4 4PU \\ United Kingdom \\ c.kotsogiannis@exeter.ac.uk
}

\author{
Robert Schwager \\ Georg-August-University \\ Platz der Göttinger Sieben 3 \\ 37073 Göttingen \\ Germany \\ rschwag@uni-goettingen.de
}

November 10, 2006

This is a revised version of a paper presented at the IFIR/CESIfo Conference on 'New Directions in Fiscal Federalism', Lexington, Kentucky, September 14th-16th, 2006. We thank our discussant, Ernesto Crivelli, and the participants of the conference for comments and suggestions. Kotsogiannis acknowledges the support provided by the Catalan Government Science Network (Project No. SGR2005-177). 


\section{Introduction}

A common feature of federal economies is the existence of fiscal equalization programs that entail monetary transfers from jurisdictions ('states' or 'provinces') with aboveaverage fiscal capacity to jurisdictions with lower-than-average fiscal capacity. These transfers thus ensure that have-not jurisdictions have the necessary fiscal capacity to guarantee themselves the national average level of public services per resident without imposing higher than average tax rates.

It is well understood that such equalization transfers have efficiency consequences for the level of taxation, by distorting fiscal policy incentives for receiving governments. For, equalization transfers, by compensating jurisdictions for the adverse effect of an increased tax rate on the tax base (of the form familiar from Wildasin (1989)), induce those jurisdictions to raise taxes higher than it is desirable from a national point of view, Smart (1998). Of course, federal transfers that induce higher levels of effort might not be welfare decreasing from a national point of view if equilibrium local tax rates are too low (Köthenbürger (2002), and Bucovetsky and Smart (2006)). ${ }^{1}$

The implementation of any system of equalization transfers that is based on fiscal capacities is bound to be complicated for two reasons. Firstly, there is the measurement of actual tax bases. In the absence, as is typically the case, of collection agreements for most tax bases, jurisdictions can and often define their own tax bases quite differently, (see, Boadway (1998), (2004), and Smart (2005), for the Canadian equalization program). Secondly, equalization formulae are typically complex lending support to the view of equalization programs as being non-transparent and therefore less subject to democratic accountability than other government policies. It is conceivable then - and indeed it is shown this here to be the case - that such transfers, by equalizing fiscal capacity between jurisdictions in a rather nontransparent manner, may interact with the incentives of policy makers to divert resources away from public good provision and for personal gain. This possibility, though it has, implicitly or explicitly, appeared in policy discussions has not attracted, to the best of our knowledge, any formal analysis. And this is the objective of this paper: to develop a model within which issues of accountability and equalization transfers can be articulated and investigated. It is shown that an equalization system reduces the intensity of political competition and as such is conducive to more rent-seeking activities.

The analysis of political competition presented here takes up the idea of relative per-

\footnotetext{
${ }^{1}$ Empirical evidence for the impact of equalization on the tax setting behavior of lower level jurisdictions is provided by Dahlby and Warren (2003) for Australia, Karkalakos and Kotsogiannis (2006) for Canada, and Büttner (2006) for Germany.
} 
formance evaluation popularized in Public Finance by Besley and Case (1995). ${ }^{2}$ These contributions consider the effect of 'yardstick' competition on rent extraction and in particular on the selection of 'good' incumbents. Like in these models, in the present paper voters of a typical jurisdiction can evaluate the incumbent of their jurisdiction using information obtained from observing the behavior of a neighboring jurisdiction. Unlike these contributions, however, we consider the interaction between equalization transfers and the incentives arising from elections.

We explore this aspect by considering a simple two period model with career concerns and yardstick competition between the incumbents of two jurisdictions. ${ }^{3}$ In this model, the fiscal capacity and thus the supply of public goods in a jurisdiction are affected by the 'competence' and the extent of rent-seeking behavior of the local incumbent, but also by a shock which is common across jurisdictions. Since voters cannot observe competence and rent-seeking behavior nor the common shock, they assess the performance of the incumbent in their own jurisdiction by comparing public goods supplies across jurisdictions. An incumbent who takes more rents will see her jurisdiction fare worse in this comparison and, thus, her chances of re-election are reduced.

We introduce a system of horizontal intergovernmental transfers into this setup where a fraction of the difference between the jurisdictions' fiscal capacities is equalized. To capture the complexity of the equalization transfer, emphasized in the preceding paragraphs, we introduce a random component in the determination of the fiscal capacity of jurisdictions by the agents. ${ }^{4}$ Therefore, even knowing the equalization rate, citizens cannot perfectly derive fiscal capacities from the supplies of public goods observed in both jurisdictions. Hence, the informational content of the comparison across jurisdictions is reduced. By consequence, the adverse effect of increased rent-seeking by an incumbent on voters' assessment of her performance is mitigated by equalization transfers. Thus, the incumbent politician's trade-off between current rents and the probability of winning the elections is tilted towards more rent diversion. Based on this effect, it is shown that the amount of rents taken in a (symmetric) Nash equilibrium increases in the equalization rate. This suggests that equalization payments may adversely affect the working of the political system and be conducive to misbehavior by incumbents.

\footnotetext{
${ }^{2}$ This theory has been further developed by, among others, Besley and Smart (2003), Bordignon et al. (2004), Belleflamme and Hindriks (2005), and Revelli (2006).

${ }^{3}$ As in Persson and Tabellini (2000), chapter 9.

${ }^{4}$ One, of course, may argue that interested parties may have the incentive (if they have the capability of doing so) to precisely calculate fiscal capacities and inform voters, Smart (2005). Though this is a possibility it does not seem to be a perfectly convincing one. For interested parties, typically, have opposing incentives in the calculation of fiscal capacities giving scope for unlimited conflict over transfers. This conflict, as far as the true fiscal capacities of the jurisdictions are concerned, is unlikely to be very informative and, therefore, some uncertainty will still linger.
} 
Our work is part of the fast growing literature, termed the second-generation theory of fiscal federalism (SGTF), that focuses on the political processes and the behavior of political agents and their effects on fiscal outcomes in federal systems (see Oates (2005), and Weingast (2006) for comprehensive surveys on the SGTF literature). While identifying institutions and political incentives rather than preferences and technology as the driving forces, this line of research, like the first generation theory of fiscal federalism, aims at explaining the main characteristics of federal systems, such as the vertical allocation of powers or equalization transfers. Consequently, a first and major task has been to develop a political theory of the benefits and drawbacks of decentralization (see Seabright (1996), Persson and Tabellini (2000), Lockwood (2002), and Hindriks and Lockwood (2005)).

Equalization transfers, which are at the heart of our analysis, have also received some attention in the second-generation theory of fiscal federalism. For example, Inman (1998) and Johansson (2003) provide a rationale for the empirical observation that variations in transfers to jurisdictions cannot be explained by traditional concerns of equity and efficiency alone. Variables representing political incentives are additional and significant determinants of these transfers. While this is an important issue, our focus here is not on the political causes of equalization, but rather on the interplay between accountability and equalization transfers. This issue is briefly touched upon in Smart (2005). More formally, Careaga and Weingast (2003) show that the common pool problem created by revenue sharing induces lower level governments to divert resources away from productive use, a prediction validated by empirical results from Mexican states. Similarly, Baretti et al. (2002) show that the outflow of tax revenues caused by equalization reduces the efforts by German states to enforce and collect federal taxes. Finally, Boarnet and Glazer (2002) show that spending in U.S. states is lower when neighboring states obtain larger federal grants. According to this latter contribution this occurs because politicians at the state level are considered to be incompetent when they fail to win federal grants and as consequence a rational response by voters is to force them cut public spending. To this line of research, which is mainly empirical in nature, our work contributes by

providing a formal model suitable to analyze the impact of fiscal equalization on the political incentives provided by elections.

The organization of the paper is as follows. Section 2 introduces the model while Section 3 presents its equilibrium. Section 4 briefly concludes.

\section{Description of the model}

We consider a model with two periods and two jurisdictions labeled $i=1,2$ which are ex ante identical. There is electoral accountability in the sense that voters hold incumbents 
accountable ex post for incompetent behavior in office. This occurs in an election at the end of period 1 (described in subsection 2.3). There is a representative citizen in each jurisdiction whose income per period is normalized, for convenience, to 1 . The citizen pays an exogenously fixed tax of $\bar{\tau}$ per period. The supply of the public good in jurisdiction $i=1,2$ in period 1 is denoted by $g_{i}$, whereas $g_{i}^{2}$ denotes public good supply in period 2. ${ }^{5}$ The supply of public goods in each period is determined by the fiscal capacity of a given jurisdiction (introduced in subsection 2.1) and the fiscal equalization scheme that is in place (introduced in subsection 2.2).

\subsection{Determination of fiscal capacity}

Fiscal capacity $\tau_{i}$ in jurisdiction $i=1,2$ depends on the 'ability' (equivalently 'competence') of the incumbent politician in the given jurisdiction, denoted by $\eta_{i}$, the common economic environment of the federation $\varepsilon$, and the actions of the incumbent politician in terms of the resources diverted away from public good provision towards own consumption, denoted by $r_{i}$. The competence level $\eta_{i}$, which is a permanent feature of incumbent $i=1,2$, and the economic environment of the federation $\varepsilon$, which is common to both jurisdictions, are both stochastic and unknown to both voters and incumbents. In particular, the abilities of first period incumbents are identically and independently distributed normal random variables with mean $\mu_{\eta}=1$ and variance $\sigma_{\eta}^{2}$. The common shock $\varepsilon$ is normally distributed with mean $\mu_{\varepsilon}=0$ and variance $\sigma_{\varepsilon}^{2}$, and is independent from both competence levels $\eta_{1}$ and $\eta_{2}$.

In period 1 , the incumbent politician in jurisdiction $i=1,2$ decides to take rents $r_{i}$, out of the tax revenues collected $\bar{\tau}$. These choices are not observed by voters before the election. Rents cannot, of course, be negative and so $r_{i} \geq 0, i=1,2$. It is also assumed that rents satisfy $\bar{\tau}>\bar{r} \geq r_{i}, i=1,2 .{ }^{6}$ The remaining revenues $\bar{\tau}-r_{i}$ are transformed into fiscal capacities $\tau_{i}$ as follows

$$
\tau_{i}=\left(\eta_{i}+\varepsilon\right)\left(\bar{\tau}-r_{i}\right), \quad i=1,2
$$

Equation (1) simply states that, ceteris paribus, the higher the level of competence of the incumbent of a jurisdiction the higher the fiscal capacity of that jurisdiction. Similarly, the better the economic environment of the federation, all other things being equal, the better the fiscal capacity of both jurisdictions.

\footnotetext{
${ }^{5}$ We denote, throughout, second period variables by the superscript 2. Also, for ease of notation, we drop the time index for variables relating to the first period.

${ }^{6} \mathrm{~A}$ possible, and arguably convincing, reason for this restriction is the possibility that a zero provision of public goods triggers an immediate investigation by an independent authority, such as the constitutional court, into the workings of the government.
} 


\subsection{The fiscal equalization program}

In practice a typical tax-base-equalization program has the following structure. For the revenue source a base is chosen to represent, as closely as possible, the actual base of that revenue source. Total revenues for all jurisdictions from that source are then divided by the nationwide base to arrive at a 'national average revenue rate'. This rate is then applied to the base in a particular jurisdiction and the resulting tax is divided by the provincial population to obtain the per capita yield of the tax at the national average rate. The difference between the jurisdiction's per capita yield and the national per capita yield, multiplied by the jurisdiction's population, represents the base for calculating the equalization payments due to the jurisdiction with respect to that particular revenue source. If the difference is negative (positive), a certain fraction of the difference, called the equalization rate, is paid out to (collected from) the jurisdiction. ${ }^{7}$

As noted in the introductory section, the assessment of fiscal capacity in equalization programs is inherently complex. To capture this complexity we introduce the random variable $^{8} \Gamma_{i}, i=1,2$, and assume that the fiscal capacity of jurisdiction $i=1,2$ is overestimated by the amount $\Gamma_{i}$. It is thus the value of $\tau_{i}+\Gamma_{i}$, instead of the true fiscal capacity $\tau_{i}$, that enters the equalization formula. The specific form of this variable is given by

$$
\Gamma_{i}=\left(\bar{\tau}-r_{j}\right) \gamma_{i}, \quad i=1,2,
$$

where $\gamma_{i}$ is normally distributed with mean $\mu_{\gamma}=0$ and variance $\sigma_{\gamma}^{2}$. The random variable $\gamma_{i}, i=1,2$, is unknown both to voters and incumbents, they are independent from each other, and also independent from $\eta_{1}, \eta_{2}$, and $\varepsilon$. This formulation reflects the idea that in each jurisdiction $i$ there is an exogenous source of measurement error $\gamma_{i}$ per unit of revenues so that the total error is proportional to the average revenues spent for public good provision. Thus, the random element of the equalization scheme has the same order of magnitude as the incumbent's competence and the overall economic shock. Consequently, a change in rent-taking does not directly affect the relative importance of the incumbent's ability in determining the supply of public goods.

\footnotetext{
${ }^{7}$ This is, for instance, a variant of the equalization systems in Canada and Germany. In Canada the equalization rate is constant (derived from using a five-province standard) and the 'gross system' is applicable whereby only positive equalization entitlements are paid. In Germany the equalization rate varies with the difference between the jurisdiction's own fiscal capacity and the average fiscal capacity in the federation but the 'net system' is applicable whereby both positive and negative transfers exist.

${ }^{8}$ While we rather interpret the shock $\Gamma_{i}, i=1,2$, as a mistake in the assessment of fiscal capacity, as noted in the introductory section, one might also think of this as a deliberate deviation from pure equalization. Such a deviation might be enacted by the federal government so as to favor some particular jurisdiction. For the present analysis this interpretation would fit the model as long as this bias in the federal government's policy cannot be predicted by voters nor local incumbents. Another possible interpretation might be that citizens do not fully observe and understand the mechanics of the equalization system.
} 
The equalization transfer to jurisdiction $i=1,2$ is, then, given by

$$
z_{i}=t\left[\frac{\sum_{j=1,2}\left(\tau_{j}+\Gamma_{j}\right)}{2}-\left(\tau_{i}+\Gamma_{i}\right)\right],
$$

where $1 \geq t \geq 0$ is the federation's equalization rate. Naturally, since the budget of the federal economy must balance, we have that $\Sigma_{i} z_{i}=0$.

Public good provision in jurisdictions $i=1,2$ is, then, given by

$$
\begin{aligned}
g_{i} & =\tau_{i}+z_{i}, \\
& =\tau_{i}+(t / 2)\left(\tau_{j}-\tau_{i}+\Gamma_{j}-\Gamma_{i}\right),
\end{aligned}
$$

where the second equality follows from (3), and $j \in\{1,2\}, j \neq i$ denotes the other jurisdiction.

Making now use of (2) in (4) for both jurisdictions and solving these equations simultaneously, one obtains, for $i=1,2$ and $j \in\{1,2\}, j \neq i$, the level of fiscal capacities $\tau_{i}$ conditional upon the public good supplies in the own and other jurisdiction, $g_{i}$ and $g_{j}$, respectively, that is

$$
\tau_{i}=g_{i}+\theta\left(g_{i}-g_{j}+\Gamma_{i}-\Gamma_{j}\right)
$$

where

$$
\theta(t)=t / 2(1-t) \geq 0
$$

The inequality in (6) follows from the restriction on the equalization rate. Notice now, for later use, that, following $(6)^{9}$

$$
\theta^{\prime}(t)=2(1-t)^{-2}>0
$$

and so $\theta$ is a monotonically increasing function of the equalization rate $t$. However, since citizens are not informed about $\gamma_{1}$ nor $\gamma_{2}$ they cannot infer fiscal capacities from the observation of $g_{1}$ and $g_{2}$. Instead, they must form expectations about fiscal capacities, and the underlying competence levels of the incumbents.

\subsection{Payoffs and second period decisions}

In period 2, fiscal capacities and the equalization scheme determine public goods supplies $g_{i}^{2}, i=1,2$, just as in period 1 , by equations analogous to (1)-(4). For the fiscal capacity in jurisdiction $i=1,2$, however, now the competence of the government in the second period is relevant. This is either the competence $\eta_{i}$ of the first period incumbent, if the latter is re-elected, or, if she is defeated, the competence of a challenger which is drawn

\footnotetext{
${ }^{9} \mathrm{~A}$ prime denotes the derivative of a function of one variable.
} 
from the same normal distribution with mean $\mu_{\eta}=1$ and variance $\sigma_{\eta}$. Moreover, the second period government decides on a second period rent $r_{i}^{2}$ which satisfies the same restrictions as the first period rent, that is, $r_{i}^{2} \geq 0$ and $\bar{\tau}>\bar{r} \geq r_{i}^{2}, i=1,2$.

Politicians are interested in expropriating rents collected in both periods and in an exogenous additional rent from winning the elections, denoted by $R>0$. Denoting by $\delta$ the discount factor and by $p_{I, i}$ the probability that the incumbent of jurisdiction $i=1,2$ is re-elected for office in the second period, the payoff to the incumbent of jurisdiction $i$ is given by

$$
r_{i}+p_{I, i} \cdot \delta\left(R+r_{i}^{2}\right)
$$

Citizens value public goods more than private consumption. Thus, for some constant $\alpha>1$, the utility of citizens in jurisdiction $i=1,2$ is given by

$$
u_{i}=1-\bar{\tau}+\alpha g_{i}+\delta\left(1-\bar{\tau}+\alpha g_{i}^{2}\right)
$$

In the second period there is no re-election motive anymore and thus every government will take the maximal rent $r_{i}^{2}=\bar{r}, i=1,2$. Nevertheless, given that $\bar{\tau}>\bar{r}$, there always remains some tax revenue which is used for public good provision. Thus for given maximal rent-taking behavior a more competent incumbent still produces a higher fiscal capacity. Now, as can be seen from (4), for all equalization rates $0 \leq t \leq 1$, the supply of public goods in a jurisdiction is increasing in the fiscal capacity of this jurisdiction. Therefore, a more competent government in a jurisdiction will deliver a higher quantity of the public good to that jurisdiction's citizens. Hence, the citizens in both jurisdictions have an incentive to elect the most competent incumbent. Consequently, in the election at the end of the first period voters in jurisdiction $i=1,2$ vote for the incumbent if their estimate of the incumbent's ability $\tilde{\eta}_{i}$ exceeds the expected ability of the challenger, which is given by $\mu_{\eta}=1$.

\section{Equilibrium analysis}

The model is analyzed using the Nash equilibrium concept under which the decisions by voters and incumbents in the first period are simultaneously optimal, given a correct assumption on the other players' behavior. Following this the optimal voting behavior of citizens in jurisdiction $i=1,2$ is determined by the estimate $\tilde{\eta}_{i}$ they form about the competence of the incumbent in this jurisdiction. This estimate is based on the information citizens have at that moment and on an assumption about the rent-taking behavior of both incumbents, denoted by $\tilde{r}_{i}$, for $i=1,2 .{ }^{10}$ In subsection 3.1, the formation of the expectation $\tilde{\eta}_{i}, i=1,2$, conditional on $\tilde{r}_{i}$ and $\tilde{r}_{j}$, for $j \in\{1,2\}, j \neq i$, is analyzed.

\footnotetext{
${ }^{10}$ The supposed strategies $\tilde{r}_{i}, i=1,2$, just as the rents $r_{i}, i=1,2$, actually chosen, do not depend on the levels of competence $\eta_{i}$ since when the rents are chosen competence is not known to the incumbents.
} 
The incumbent of jurisdiction $i=1,2$ decides about how much rents $r_{i}$ to expropriate anticipating the impact of this decision on the estimate $\tilde{\eta}_{i}$ and, hence, on the probability of winning the election. This is described in subsection 3.2. An equilibrium requires that the actual decisions coincide with the assumptions used by the voters, that is, $\tilde{r}_{i}=r_{i}$ for $i=1,2$. To keep the analysis tractable, we restrict attention to symmetric equilibria where the incumbents of both jurisdictions take the same rent $r$, that is, $r_{1}=r_{2}=r$. In subsection 3.3 the rent taken in such an equilibrium is calculated. The analysis is then completed by deriving the impact of an increase in the equalization rate on this rent.

\subsection{The citizens' estimate of the incumbent's ability}

To describe how voters in jurisdiction $i=1,2$ rationally form the estimate $\tilde{\eta}_{i}$, consider the information they possess at the time of the elections. They know that the incumbent maximizes (8), and they also know the level of tax $\bar{\tau}$ as well as the equalization rate $t$. Moreover, they observe the level of public good supplied in both jurisdictions $g_{i}, i=1,2$.

It is convenient to describe the citizens' estimate in terms of a statistic $S_{i}$ defined for $i=1,2$ and $j \in\{1,2\}, j \neq i$, by

$$
S_{i} \stackrel{\text { def }}{=} \frac{g_{i}+\theta\left(g_{i}-g_{j}\right)}{\bar{\tau}-\tilde{r}_{i}} .
$$

It is intuitive that the statistic in (10) uses only the information available to the voters, together with the assumption $\tilde{r}_{i}$ about the amount of rents diverted by incumbent $i$ in period 1. Following from (5), the statistic in the definition in (10) becomes

$$
S_{i}=\frac{\tau_{i}+\theta\left(\Gamma_{j}-\Gamma_{i}\right)}{\bar{\tau}-\tilde{r}_{i}} .
$$

If citizens now believe that $\tilde{r}_{1}$ and $\tilde{r}_{2}$ are being chosen by the incumbents then they will believe that fiscal capacities and measurement errors are given by $\tau_{i}=\left(\eta_{i}+\varepsilon\right)\left(\bar{\tau}-\tilde{r}_{i}\right)$ and $\Gamma_{i}=\left(\bar{\tau}-\tilde{r}_{i}\right) \gamma_{i}, i=1,2$. This, in turn, implies-following (11)-that for $i=1,2$ and $j \in\{1,2\}, j \neq i$,

$$
S_{i}=\eta_{i}+\varepsilon+\theta\left(\tilde{\rho}_{j} \gamma_{j}-\gamma_{i}\right)
$$

where

$$
\tilde{\rho}_{j} \stackrel{\text { def }}{=} \frac{\bar{\tau}-\tilde{r}_{j}}{\bar{\tau}-\tilde{r}_{i}}
$$

Equation (12) shows why it is useful to define the particular statistics $S_{i}, i=1,2$. As seen from (5), the numerators in $S_{i}$ (in (10)) are naive estimates of the fiscal capacity in the respective jurisdiction, which are obtained by ignoring the assessment mistakes $\Gamma_{i}, i=$ 1,2. By dividing this estimate through the tax rate after the presumed rent one obtains a random number which is additively composed of the competence of the incumbent in one's own jurisdiction and the random shocks. Thus, for both jurisdictions $i=1,2$, citizens' estimate $\tilde{\eta}_{i}$ of the ability of the $i$-incumbent can be determined additively from 
the observed statistic $S_{i}$ and the expected values of $\varepsilon, \gamma_{1}$, and $\gamma_{2}$, conditional on the information summarized in the statistics $S_{1}$ and $S_{2}$.

Denoting these conditional expectations by $E\left(\varepsilon \mid S_{1}, S_{2}\right)$ and $E\left(\gamma_{i} \mid S_{1}, S_{2}\right)$ for $i=1$, 2 , one so obtains from (12) for $i=1,2$ and $j \in\{1,2\}, j \neq i$,

$$
\tilde{\eta}_{i}=S_{i}-E\left(\varepsilon \mid S_{1}, S_{2}\right)+\theta\left[E\left(\gamma_{i} \mid S_{1}, S_{2}\right)-\tilde{\rho}_{j} E\left(\gamma_{j} \mid S_{1}, S_{2}\right)\right]
$$

In equation (14), the five random variables $\left(\varepsilon, \gamma_{1}, \gamma_{2}, S_{1}, S_{2}\right)$ determine the estimate $\tilde{\eta}_{i}$. Now following from $(12),\left(\varepsilon, \gamma_{1}, \gamma_{2}, S_{1}, S_{2}\right)=\left(\varepsilon, \gamma_{1}, \gamma_{2}, \eta_{1}+\varepsilon+\theta\left(\tilde{\rho}_{2} \gamma_{2}-\gamma_{1}\right), \eta_{2}+\varepsilon+\right.$ $\left.\theta\left(\tilde{\rho}_{1} \gamma_{1}-\gamma_{2}\right)\right)$. Hence the joint distribution of the random vector $\left(\varepsilon, \gamma_{1}, \gamma_{2}, S_{1}\right.$, $\left.S_{2}\right)$, as perceived by the citizens, is the same as for the vector of random variables $\left(\varepsilon, \gamma_{1}, \gamma_{2}, \eta_{1}+\right.$ $\left.\varepsilon+\theta\left(\tilde{\rho}_{2} \gamma_{2}-\gamma_{1}\right), \eta_{2}+\varepsilon+\theta\left(\tilde{\rho}_{1} \gamma_{1}-\gamma_{2}\right)\right)$. In Appendix A.1 it is shown that, based on this identity, the citizens' estimate of the incumbent's ability is, for $i=1,2$ and $j \in\{1,2\}, j \neq i$, given by

$$
\begin{aligned}
\tilde{\eta}_{i}= & \frac{\sigma_{\eta}^{2}\left[\sigma_{\eta}^{2}+\sigma_{\varepsilon}^{2}+\theta^{2}\left(\tilde{\rho}_{i}^{2}+1\right) \sigma_{\gamma}^{2}\right]}{\left|\Sigma_{22}\right|} \cdot S_{i}-\frac{\sigma_{\eta}^{2}\left[\sigma_{\varepsilon}^{2}-\theta^{2}\left(\tilde{\rho}_{i}+\tilde{\rho}_{j}\right) \sigma_{\gamma}^{2}\right]}{\left|\Sigma_{22}\right|} \cdot S_{j} \\
& +\frac{2 \sigma_{\eta}^{2} \sigma_{\varepsilon}^{2}+\theta^{2}\left\{\left(\tilde{\rho}_{i}+\tilde{\rho}_{j}\right)\left(\tilde{\rho}_{j}-1\right) \sigma_{\eta}^{2}+\left[\left(\tilde{\rho}_{i}+1\right)^{2}+\left(\tilde{\rho}_{j}+1\right)^{2}\right] \sigma_{\varepsilon}^{2}\right\} \sigma_{\gamma}^{2}}{\left|\Sigma_{22}\right|}
\end{aligned}
$$

with

$$
\left|\Sigma_{22}\right|=\sigma_{\eta}^{2}\left(\sigma_{\eta}^{2}+2 \sigma_{\varepsilon}^{2}\right)+\theta^{2}\left\{\left(\tilde{\rho}_{i}+\tilde{\rho}_{j}\right)^{2} \sigma_{\eta}^{2}+\left[\left(\tilde{\rho}_{i}+1\right)^{2}+\left(\tilde{\rho}_{j}+1\right)^{2}\right] \sigma_{\varepsilon}^{2}\right\} \sigma_{\gamma}^{2} .
$$

Equation (15) shows, clearly, the working of yardstick competition in this model. When evaluating the performance of the incumbent in their own jurisdiction, citizens in jurisdiction $i$ do not only consider the signal $S_{i}$ that relates to the fiscal capacity in jurisdiction $i$, but also the signal $S_{j}$ that relates to the neighboring jurisdiction $j$.

We now turn to analyzing how the incumbent in jurisdiction $i$ uses the estimate derived in (15) in order to assess her probability of winning the election.

\subsection{The incumbent's decision in jurisdiction $i$}

As explained in subsection 2.3, voters will re-elect the incumbent of jurisdiction $i$ if the estimate in (15) is at least as large as the expected competence of the challenger, $\mu_{\eta}=1$. Thus, when choosing rents $r_{i}$ in period 1 , the incumbent politician of jurisdiction $i$ perceives the probability of her re-election to be $p_{I, i}=\operatorname{Prob}\left\{\tilde{\eta}_{i} \geq \mu_{\eta}\right\}=\operatorname{Prob}\left\{\tilde{\eta}_{i} \geq 1\right\}$. Central to this choice problem for the incumbent is the impact of an increase in the rent $r_{i}$ on this probability.

The probability distribution of $\tilde{\eta}_{i}$ depends on the distribution of the federation-wide shock $\varepsilon$ and of the measurement errors $\gamma_{1}$ and $\gamma_{2}$ but also on the distribution of the 
competence $\eta_{j}$ of the incumbent in the other jurisdiction $j \neq i$, since the statistic $S_{j}$, which depends on $\eta_{j}$, enters $\tilde{\eta}_{i}$ in (15). Moreover, since, by assumption, the incumbent does not know her competence, the distribution of $\tilde{\eta}_{i}$ also depends on the distribution of $\eta_{i}$ (and not the realization of $\eta_{i}$ drawn by the particular incumbent). In addition to the random variables, $\tilde{\eta}_{i}$ is also affected by the strategies $\tilde{r}_{1}$ and $\tilde{r}_{2}$ supposed by the citizens, which are given for the politicians, and, hence, can be treated as parameters. However, by choosing the actual strategy $r_{i}$, the incumbent of jurisdiction $i$ affects fiscal capacity $\tau_{i}$ and hence, via the equalization program, both statistics $S_{1}$ and $S_{2}$. Thus, by choosing the rent $r_{i}$ the incumbent influences the observation available to voters. Similarly, the rent $r_{j}$ actually taken by the incumbent in the other jurisdiction $j \neq i$ affects $\tilde{\eta}_{i}$ by influencing $\tau_{j}$ and hence $S_{1}$ and $S_{2}$.

To obtain the probability distribution of $\tilde{\eta}_{i}$ in equation (15) we follow this reasoning and replace, for $i=1,2, \tau_{i}=\left(\eta_{i}+\varepsilon\right)\left(\bar{\tau}-r_{i}\right)$ and $\Gamma_{i}=\left(\bar{\tau}-r_{i}\right) \gamma_{i}$ in $S_{i}$ from (11). In doing so one obtains for both $i=1,2$, and $j \in\{1,2\}, j \neq i$

$$
S_{i}=\frac{\bar{\tau}-r_{i}}{\bar{\tau}-\tilde{r}_{i}}\left(\eta_{i}+\varepsilon\right)+\theta \frac{\left(\bar{\tau}-r_{j}\right) \gamma_{j}+\left(\bar{\tau}-r_{i}\right) \gamma_{i}}{\bar{\tau}-\tilde{r}_{i}}
$$

Making use of (17) for both jurisdictions in (15), it is shown in Appendix A.2, that the estimate $\tilde{\eta}_{i}$, for $i=1,2, j \in\{1,2\}, j \neq i$, can be written as a weighted sum of independent normal random variables

$$
\tilde{\eta}_{i}=a_{1}\left(r_{i}\right) \eta_{i}+a_{2}\left(r_{j}\right) \eta_{j}+a_{3}\left(r_{i}, r_{j}\right) \varepsilon+a_{4}\left(r_{i}\right) \gamma_{i}+a_{5}\left(r_{j}\right) \gamma_{j}+a_{o}
$$

The notation illustrates that the weights are functions of the strategies $r_{i}$ and $r_{j}$, while their dependence on the equalization parameter $\theta$, for brevity, is not displayed. From (18), $\tilde{\eta}_{i}$ is itself normally distributed. Using this fact, and making use of $E(\varepsilon)=E\left(\gamma_{i}\right)=$ 0 and $E\left(\eta_{i}\right)=1$ for $i=1,2$, one can straightforwardly show that the expectation and variance of the distribution of $\tilde{\eta}_{i}$, are given, respectively, by

$$
\begin{aligned}
\mu_{i}\left(r_{1}, r_{2}, \theta\right)= & a_{1}\left(r_{i}\right) E\left(\eta_{i}\right)+a_{2}\left(r_{j}\right) E\left(\eta_{j}\right)+a_{3}\left(r_{i}, r_{j}\right) E(\varepsilon) \\
& +a_{4}\left(r_{i}\right) E\left(\gamma_{i}\right)+a_{5}\left(r_{j}\right) E\left(\gamma_{j}\right)+a_{o} \\
= & a_{1}\left(r_{i}\right)+a_{2}\left(r_{j}\right)+a_{0}, \\
\sigma_{i}^{2}\left(r_{1}, r_{2}, \theta\right)= & {\left[a_{1}\left(r_{i}\right)\right]^{2} \operatorname{Var}\left(\eta_{i}\right)+\left[a_{2}\left(r_{j}\right)\right]^{2} \operatorname{Var}\left(\eta_{j}\right)+\left[a_{3}\left(r_{i}, r_{j}\right)\right]^{2} \operatorname{Var}(\varepsilon) } \\
& +\left[a_{4}\left(r_{i}\right)\right]^{2} \operatorname{Var}\left(\gamma_{i}\right)+\left[a_{5}\left(r_{j}\right)\right]^{2} \operatorname{Var}\left(\gamma_{j}\right) \\
= & \left\{\left[a_{1}\left(r_{i}\right)\right]^{2}+\left[a_{2}\left(r_{j}\right)\right]^{2}\right\} \sigma_{\eta}^{2}+\left[a_{3}\left(r_{i}, r_{j}\right)\right]^{2} \sigma_{\varepsilon}^{2} \\
& +\left\{\left[a_{4}\left(r_{i}\right)\right]^{2}+\left[a_{5}\left(r_{j}\right)\right]^{2}\right\} \sigma_{\gamma}^{2},
\end{aligned}
$$

where $a_{0}, a_{1}, a_{2}, a_{3}, a_{4}$ and $a_{5}$ are defined in (A.6) in the Appendix, and $j \in\{1,2\}, j \neq i$. Having computed the expectation and variance of the distribution of $\tilde{\eta}_{i}$, we are now in a position to solve the maximization problem of the incumbent in jurisdiction $i$. Following 
from (8), the incumbent chooses $r_{i}$ to maximize $r_{i}+\operatorname{Prob}\left\{\tilde{\eta}_{i} \geq 1\right\} \cdot \delta(R+\bar{r})$, with necessary condition given by

$$
1+\frac{\partial \operatorname{Prob}\left\{\tilde{\eta}_{i} \geq 1\right\}}{\partial r_{i}} \cdot \delta(R+\bar{r})=0
$$

Using normality, the re-election probability is given by

$$
\operatorname{Prob}\left\{\tilde{\eta}_{i} \geq 1\right\}=1-F\left(1 ; \mu_{i}\left(r_{1}, r_{2}, \theta\right), \sigma_{i}^{2}\left(r_{1}, r_{2}, \theta\right)\right)
$$

where $F\left(\tilde{\eta}_{i} ; \mu_{i}, \sigma_{i}^{2}\right)$ is the normal distribution with mean $\mu_{i}$ and variance $\sigma_{i}^{2}$, and $\mu_{i}\left(r_{1}, r_{2}, \theta\right)$, $\sigma_{i}^{2}\left(r_{1}, r_{2}, \theta\right)$ are as defined in (19) and (20), respectively.

Using the re-election probability in (22), the first order condition in (21) becomes

$$
1-\left[\frac{\partial F\left(1 ; \mu_{i}, \sigma_{i}^{2}\right)}{\partial \mu_{i}} \cdot \frac{\partial \mu_{i}\left(r_{1}, r_{2}, \theta\right)}{\partial r_{i}}+\frac{\partial F\left(1 ; \mu_{i}, \sigma_{i}^{2}\right)}{\partial \sigma_{i}^{2}} \cdot \frac{\partial \sigma_{i}^{2}\left(r_{1}, r_{2}, \theta\right)}{\partial r_{i}}\right] \cdot \delta(R+\bar{r})=0 .
$$

Notice that, for later use, differentiation of $F\left(1 ; \mu_{i}, \sigma_{i}^{2}\right)$ with respect to $\mu_{i}$ gives

$$
\frac{\partial F\left(1 ; \mu_{i}, \sigma_{i}^{2}\right)}{\partial \mu_{i}}=-f\left(1 ; \mu_{i}, \sigma_{i}^{2}\right)=-\frac{1}{\sigma_{i} \sqrt{2 \pi}} e^{-\frac{1}{2}\left(\frac{1-\mu_{i}}{\sigma_{i}}\right)^{2}}
$$

where $f(\cdot)$ is the density of the $\left(\mu_{i}, \sigma_{i}^{2}\right)$-normal distribution. Moreover, using

$$
a_{1}\left(r_{i}\right)=\frac{\sigma_{\eta}^{2}\left[\sigma_{\eta}^{2}+\sigma_{\varepsilon}^{2}+\theta^{2}\left(\tilde{\rho}_{i}^{2}+1\right) \sigma_{\gamma}^{2}\right]}{\left|\Sigma_{22}\right|} \cdot \frac{\bar{\tau}-r_{i}}{\bar{\tau}-\tilde{r}_{i}}
$$

(that appears in (19) and is formally stated in (A.6)) we have that

$$
\frac{\partial \mu_{i}\left(r_{1}, r_{2}, \theta\right)}{\partial r_{i}}=a_{1}^{\prime}\left(r_{i}\right)=-\frac{\sigma_{\eta}^{2}\left[\sigma_{\eta}^{2}+\sigma_{\varepsilon}^{2}+\theta^{2}\left(\tilde{\rho}_{i}^{2}+1\right) \sigma_{\gamma}^{2}\right]}{\left|\Sigma_{22}\right|\left(\bar{\tau}-\tilde{r}_{i}\right)}
$$

We turn now to the characterization of the equilibrium.

\subsection{Characterization of the equilibrium}

We confine attention to a symmetric equilibrium, an equilibrium that is in which in both jurisdictions incumbents take the same rent $r=r_{1}=\tilde{r}_{1}=r_{2}=\tilde{r}_{2}$. Then, following from (13), $\tilde{\rho}_{1}=\tilde{\rho}_{2}=1$. This implies first that the expectation and variance of the estimates $\tilde{\eta}_{1}$ and $\tilde{\eta}_{2}$ are equal, $\mu_{i}\left(r_{1}, r_{2}, \theta\right)=\mu(r, r, \theta)$ and $\sigma_{i}^{2}\left(r_{1}, r_{2}, \theta\right)=\sigma^{2}(r, r, \theta)$ for $i=1,2$. Moreover, following from (19), the definition of the weights $a_{1}(r), a_{2}(r)$, and $a_{o}$ (as stated in $($ A.6)), and (16) one obtains $\mu(r, r, \theta)=1$. Thus, in a symmetric equilibrium the mean estimate of the incumbent's competence equals the ex ante expected competence $\mu_{\eta}$. This implies, following also from the symmetry of the normal distribution, that in equilibrium the incumbent is re-elected with probability $1-F\left(1 ; \mu(r, r, \theta), \sigma^{2}(r, r, \theta)\right)=1 / 2$. 
Since, irrespective of the variance, the normal distribution has half of the probability mass left to the mean, it is the case that

$$
\frac{\partial F\left(1 ; \mu(r, r, \theta), \sigma^{2}(r, r, \theta)\right)}{\partial \sigma^{2}}=0 .
$$

In addition, $\mu(r, r, \theta)=1$ also implies

$$
f\left(1 ; \mu(r, r, \theta), \sigma^{2}(r, r, \theta)\right)=\frac{1}{\sigma(r, r, \theta) \sqrt{2 \pi}} .
$$

Substituting (24), (26), (27), and (28) into (23), and making use of $\tilde{\rho}_{i}=1$ and $r_{i}=r$ one obtains

$$
1-\frac{1}{\sigma(r, r, \theta) \sqrt{2 \pi}} \cdot \frac{\sigma_{\eta}^{2}\left(\sigma_{\eta}^{2}+\sigma_{\varepsilon}^{2}+2 \theta^{2} \sigma_{\gamma}^{2}\right)}{\left|\Sigma_{22}\right|(\bar{\tau}-r)} \cdot \delta(R+\bar{r})=0 .
$$

The necessary condition (29) allows to characterize the behavior of the incumbents in the equilibrium. Considering the dependence of $\sigma(r, r, \theta)$ on $r$ according to (20), this equation can be solved to yield explicitly the equilibrium rent-taking, as stated in the following result.

Proposition 1 Rents taken in the first period, in a symmetric Nash equilibrium, are uniquely determined and given by

$$
r(\theta(t))=\bar{\tau}-\left(\frac{\sigma_{\eta}^{2}+\sigma_{\varepsilon}^{2}+2 \theta^{2} \sigma_{\gamma}^{2}}{\left(\sigma_{\eta}^{2}+2 \sigma_{\varepsilon}^{2}\right) \cdot\left(\sigma_{\eta}^{2}+4 \theta^{2} \sigma_{\gamma}^{2}\right) \cdot 2 \pi}\right)^{1 / 2} \cdot \delta(R+\bar{r}) .
$$

Proof of Proposition 1. See Appendix A.3.

Proposition 1 is central to the paper. Close inspection of this result reveals that the equilibrium level of rents taken by the incumbents in both jurisdictions critically depends on the variance of competence, $\sigma_{\eta}^{2}$, the variance of the federation wide economic shock, $\sigma_{\varepsilon}^{2}$, the variance of the measurement error to the equalization transfer, $\sigma_{\gamma}^{2}$, but also $\theta(t)$. It is the latter dependence that is at the center of the investigation here.

Focusing on the equalization transfer rate, $t$, one observes that, for given noises of competence, economic environment, and transfers, and as long as the equalization transfer is bounded away from zero, equalization transfers increase rent-taking behavior in a federal economy. More specifically, one can arrive at the following Proposition:

Proposition 2 With the rate of equalization bounded away from zero, an increase in the equalization rate increases equilibrium rent-taking. 
Proof of Proposition 2. See Appendix A.4.

The result of Proposition 2 shows that fiscal equalization programs tilt the incumbent politician's trade-off between current rents and the probability of winning the elections towards more rent diversion. In this trade-off, the marginal cost of an additional unit of rent diversion, determined by the loss in the probability of winning the election as given by the second term in (23), is affected by the equalization rate. To see how, observe that this marginal cost is composed of two components. First, an increase in rent-taking worsens the signal $S_{i}$, and, hence, on average citizens will attribute a lower competence to the incumbent, as expressed by the term $\partial \mu_{i} / \partial r_{i}$ in (23). Second, for each unit by which this average estimate is reduced, the probability of re-election is reduced according to the density $f=-\partial F / \partial \mu_{i}{ }^{11}$

If the equalization rate is increased, the first component of marginal cost is reduced in size. That is, with a higher equalization rate, citizens' estimate of the incumbent's competence reacts less strongly to an increase in rents $r_{i}$. This occurs because the signal $S_{i}$ is increasingly determined by the noise introduced by equalization and consequently any given change in observation produced by a given change in rents diversion is increasingly attributed by citizens to this noise rather than to competence. Essentially, equalization reduces the quality of the information available to citizens and hence rent-taking by the incumbent is less likely to be interpreted as incompetence.

Turning to the second component, we note that with an increasing equalization rate, the statistics $S_{i}, i=1,2$ vary more strongly with the noise in the equalization system, and hence they convey less information about the realization of the incumbents' competence $\eta_{i}$. Consequently, for given rent-taking strategies, the citizens have less reason to update their estimate of the competence from the ex ante expectation $\mu_{\eta}$, placing more probability mass close to the ex ante mean $\mu_{\eta}$. This implies that the density of the estimate increases if the equalization rate increases such that from this effect the marginal cost of rent diversion increases as equalization is intensified. Proposition 2 shows, however, that the first effect dominates and that the marginal cost of rent diversion is decreased by equalization.

The mistake in the assessment of fiscal capacity is crucial for the effect analyzed in Proposition 2. Thus, one should expect that if there is no such mistake that is, if $\sigma_{\gamma}^{2}=0$, the incumbent politicians cannot 'successfully' hide behind the noise that exists in the equalization system, and so choose the same rents as without equalization. Indeed this is the case. The following corollary emphasizes this:

\footnotetext{
${ }^{11}$ Recall that the second term in the square brackets in (23) is zero in a symmetric equilibrium.
} 
Corollary 1 An increase in the equalization rate t has no effect on the equilibrium rents taken by the incumbent politicians if $\sigma_{\gamma}^{2}=0$.

Proof of Corollary 1. The proof of the Corollary readily follows from equation (A.9) in the proof of Proposition 2.

The appeal of Corollary 1 (and Proposition 1) is in helping to move the discussion towards very practical policy issues. For given uncertainty in the level of competence of incumbents and the economic environment, what ultimately matters for rent diversion in a multi-jurisdictional system with elections is not equalization per se but rather how complex the implementation of the equalization program itself is. Interestingly, this result, thus, provides a theoretical foundation for the popular demand to improve transparency of equalization systems by reducing their complexity.

\section{Concluding remarks}

A lot of attention has been paid to the efficiency properties of equalization schemes. A rather neglected issue of equalization transfers is how they interact with the incentives of incumbent politicians to divert resources away from public good provision and for personal gain. This paper has explored this aspect. It was shown that an increase in the equalization rate, starting from a strictly positive rate of equalization, tilts the incentive of the incumbents towards more rent extraction.

The analysis presented here suggests a number of extensions, that we now briefly discuss. Firstly, the impact of equalization on the informational content of public goods supplies has been modeled in a rather specific way, by assuming that fiscal capacities are imperfectly measured. It remains an open question at this point whether other forms of incomplete information in the equalization program (one, for example, might be to introduce uncertainty in the equalization rate rather than the assessment of fiscal capacities) will produce similar results.

Secondly, under some circumstances equalization programs might improve, rather than impair, the information available to voters, since they might make otherwise heterogeneous jurisdictions more comparable. For such an effect to prevail, it is reasonable for one to conjecture, that the equalization system should treat local random shocks differently from the consequences of the actions taken by incompetent, or selfish, politicians. It is certainly worthwhile for future work to analyze under what conditions it is possible to implement such a scheme.

Thirdly, instead of assuming symmetric, incomplete information about the ability of the incumbent, it appears that another appealing information assumption is to suppose that 
the incumbent knows her own competence and chooses rents so as to signal her type to the electorate. Whether, and how, such signalling would be affected by the presence of equalization transfers, is an interesting and challenging question.

Finally, from a normative point of view, the result of Proposition 2 appears to suggest that equalization transfers in a federal economy have a negative impact on welfare since they may increase rent-seeking behavior. On the other hand, they do, of course, equalize fiscal capacities which, in a richer model, might provide a beneficial insurance effect (as in Lockwood, 1999). The overall impact of an equalization system on welfare, therefore, should be judged on the basis of a genuine comparison between the negative political aspect of equalization entitlements and the insurance benefit arising from the equalization of jurisdiction-specific shocks.

While these extensions are left for future research, the result presented here shows that the interaction of fiscal equalization and political incentives is an issue which deserves further attention. 


\section{Appendices}

\section{A.1 Proof of equation (15).}

The vector of random variables $\left(\varepsilon, \gamma_{1}, \gamma_{2}, S_{1}, S_{2}\right)=\left(\varepsilon, \gamma_{1}, \gamma_{2}, \eta_{1}+\varepsilon+\theta\left(\tilde{\rho}_{2} \gamma_{2}-\right.\right.$ $\left.\left.\gamma_{1}\right), \eta_{2}+\varepsilon+\theta\left(\tilde{\rho}_{1} \gamma_{1}-\gamma_{2}\right)\right)$ has an absolute continuous distribution and hence, following De Groot (1970, p. 55), its variance-covariance-matrix, denoted by $\Sigma$, is given by

$$
\begin{aligned}
\Sigma & =\left(\begin{array}{c|ccc}
\Sigma_{11} & \Sigma_{12} \\
\hline \Sigma_{21} & \Sigma_{22}
\end{array}\right) \\
& =\left(\begin{array}{ccccc}
\sigma_{\varepsilon}^{2} & 0 & 0 & \sigma_{\varepsilon}^{2} & \sigma_{\varepsilon}^{2} \\
0 & \sigma_{\gamma}^{2} & 0 & -\theta \sigma_{\gamma}^{2} & \theta \tilde{\rho}_{1} \sigma_{\gamma}^{2} \\
0 & 0 & \sigma_{\gamma}^{2} & \theta \tilde{\rho}_{2} \sigma_{\gamma}^{2} & -\theta \sigma_{\gamma}^{2} \\
\hline \sigma_{\varepsilon}^{2} & -\theta \sigma_{\gamma}^{2} & \theta \tilde{\rho}_{2} \sigma_{\gamma}^{2} & \sigma_{\eta}^{2}+\sigma_{\varepsilon}^{2}+\theta^{2}\left(\tilde{\rho}_{2}^{2}+1\right) \sigma_{\gamma}^{2} & \sigma_{\varepsilon}^{2}-\theta^{2}\left(\tilde{\rho}_{1}+\tilde{\rho}_{2}\right) \sigma_{\gamma}^{2} \\
\sigma_{\varepsilon}^{2} & \theta \tilde{\rho}_{1} \sigma_{\gamma}^{2} & -\theta \sigma_{\gamma}^{2} & \sigma_{\varepsilon}^{2}-\theta^{2}\left(\tilde{\rho}_{1}+\tilde{\rho}_{2}\right) \sigma_{\gamma}^{2} & \sigma_{\eta}^{2}+\sigma_{\varepsilon}^{2}+\theta^{2}\left(\tilde{\rho}_{1}^{2}+1\right) \sigma_{\gamma}^{2}
\end{array}\right),
\end{aligned}
$$

and its mean vector is

$$
E\left(\left(\begin{array}{c}
\varepsilon \\
\gamma_{1} \\
\gamma_{2}
\end{array}\right) \mid S_{1}, S_{2}\right)=E\left(\begin{array}{c}
\varepsilon \\
\gamma_{1} \\
\gamma_{2}
\end{array}\right)+\Sigma_{12} \cdot \Sigma_{22}^{-1} \cdot\left(\begin{array}{c}
S_{1}-1 \\
S_{2}-1
\end{array}\right) .
$$

Solving (A.2) with the help of (A.1), one finds

$$
\begin{aligned}
& E\left(\varepsilon \mid S_{1}, S_{2}\right)= \\
& \qquad \sum_{i=1,2} \frac{\sigma_{\varepsilon}^{2}}{\left|\Sigma_{22}\right|}\left[\sigma_{\eta}^{2}+\theta^{2}\left(\tilde{\rho}_{1}+\tilde{\rho}_{2}\right)\left(\tilde{\rho}_{i}+1\right) \sigma_{\gamma}^{2}\right] S_{i}-\frac{\sigma_{\varepsilon}^{2}}{\left|\Sigma_{22}\right|}\left\{2 \sigma_{\eta}^{2}+\theta^{2}\left[\sum_{i=1,2}\left(\tilde{\rho}_{i}+1\right)^{2}\right] \sigma_{\gamma}^{2}\right\}
\end{aligned}
$$

and for $i=1,2, j \in\{1,2\}, j \neq i$,

$$
\begin{aligned}
E\left(\gamma_{i} \mid S_{1}, S_{2}\right)= & -\frac{\theta \sigma_{\gamma}^{2}}{\left|\Sigma_{22}\right|}\left[\sigma_{\eta}^{2}+\left(\tilde{\rho}_{i}+1\right) \sigma_{\varepsilon}^{2}\right] S_{i}+\frac{\theta \sigma_{\gamma}^{2}}{\left|\Sigma_{22}\right|}\left[\tilde{\rho}_{i} \sigma_{\eta}^{2}+\left(\tilde{\rho}_{i}+1\right) \sigma_{\varepsilon}^{2}\right] S_{j} \\
& +\frac{\theta \sigma_{\gamma}^{2}}{\left|\Sigma_{22}\right|}\left(1-\tilde{\rho}_{i}\right) \sigma_{\eta}^{2}
\end{aligned}
$$

where $\left|\Sigma_{22}\right|$ is as in (16). Substituting (A.3)-(A.4) into (14), after some simplification, one obtains (15).

\section{A.2 Proof of equation (18).}

Upon substitution of (17) for both $i=1,2$ into (15) we obtain for $i=1,2$ and $j \in$ $\{1,2\}, j \neq i$,

$$
\begin{aligned}
\tilde{\eta}_{i}= & \frac{\sigma_{\eta}^{2}\left[\sigma_{\eta}^{2}+\sigma_{\varepsilon}^{2}+\theta^{2}\left(\tilde{\rho}_{i}^{2}+1\right) \sigma_{\gamma}^{2}\right]}{\left|\Sigma_{22}\right|} \cdot\left[\frac{\bar{\tau}-r_{i}}{\bar{\tau}-\tilde{r}_{i}}\left(\eta_{i}+\varepsilon\right)+\theta \frac{\left(\bar{\tau}-r_{j}\right) \gamma_{j}-\left(\bar{\tau}-r_{i}\right) \gamma_{i}}{\bar{\tau}-\tilde{r}_{i}}\right] \\
& -\frac{\sigma_{\eta}^{2}\left[\sigma_{\varepsilon}^{2}-\theta^{2}\left(\tilde{\rho}_{i}+\tilde{\rho}_{j}\right) \sigma_{\gamma}^{2}\right]}{\left|\Sigma_{22}\right|} \cdot\left[\frac{\bar{\tau}-r_{j}}{\bar{\tau}-\tilde{r}_{j}}\left(\eta_{j}+\varepsilon\right)+\theta \frac{\left(\bar{\tau}-r_{i}\right) \gamma_{i}-\left(\bar{\tau}-r_{j}\right) \gamma_{j}}{\bar{\tau}-\tilde{r}_{j}}\right] \\
& +\frac{2 \sigma_{\eta}^{2} \sigma_{\varepsilon}^{2}+\theta^{2}\left\{\left(\tilde{\rho}_{i}+\tilde{\rho}_{j}\right)\left(\tilde{\rho}_{j}-1\right) \sigma_{\eta}^{2}+\left[\left(\tilde{\rho}_{i}+1\right)^{2}+\left(\tilde{\rho}_{j}+1\right)^{2}\right] \sigma_{\varepsilon}^{2}\right\} \sigma_{\gamma}^{2}}{\left|\Sigma_{22}\right|} .
\end{aligned}
$$


Upon collecting terms, (A.5) simplifies to

$$
\begin{aligned}
& \tilde{\eta}_{i}=\underbrace{\frac{\sigma_{\eta}^{2}\left[\sigma_{\eta}^{2}+\sigma_{\varepsilon}^{2}+\theta^{2}\left(\tilde{\rho}_{i}^{2}+1\right) \sigma_{\gamma}^{2}\right]}{\left|\Sigma_{22}\right|} \cdot \frac{\bar{\tau}-r_{i}}{\bar{\tau}-\tilde{r}_{i}} \cdot \eta_{i}}_{a_{1}\left(r_{i}\right)}-\underbrace{\frac{\sigma_{\eta}^{2}\left[\sigma_{\varepsilon}^{2}-\theta^{2}\left(\tilde{\rho}_{i}+\tilde{\rho}_{j}\right) \sigma_{\gamma}^{2}\right]}{\left|\Sigma_{22}\right|} \cdot \frac{\bar{\tau}-r_{j}}{\bar{\tau}-\tilde{r}_{j}}}_{-a_{2}\left(r_{j}\right)} \cdot \eta_{j} \\
& +\underbrace{\frac{\sigma_{\eta}^{2}\left[\sigma_{\eta}^{2}+\sigma_{\varepsilon}^{2}+\theta^{2}\left(\tilde{\rho}_{i}^{2}+1\right) \sigma_{\gamma}^{2}\right] \cdot \frac{\bar{\tau}-r_{i}}{\bar{\tau}-\tilde{r}_{i}}-\sigma_{\eta}^{2}\left[\sigma_{\varepsilon}^{2}-\theta^{2}\left(\tilde{\rho}_{i}+\tilde{\rho}_{j}\right) \sigma_{\gamma}^{2}\right] \cdot \frac{\bar{\tau}-r_{j}}{\bar{\tau}-\tilde{r}_{j}}}{\left|\Sigma_{22}\right|}}_{a_{3}\left(r_{i}, r_{j}\right)} \cdot \varepsilon \\
& -\underbrace{\theta \cdot \frac{\sigma_{\eta}^{2}\left[\sigma_{\eta}^{2}+\sigma_{\varepsilon}^{2}+\theta^{2}\left(\tilde{\rho}_{i}^{2}+1\right) \sigma_{\gamma}^{2}\right] \cdot \frac{\bar{\tau}-r_{i}}{\bar{\tau}-\tilde{r}_{i}}+\sigma_{\eta}^{2}\left[\sigma_{\varepsilon}^{2}-\theta^{2}\left(\tilde{\rho}_{i}+\tilde{\rho}_{j}\right) \sigma_{\gamma}^{2}\right] \cdot \frac{\bar{\tau}-r_{i}}{\bar{\tau}-\tilde{r}_{j}}}{\left|\Sigma_{22}\right|}}_{-a_{4}\left(r_{i}\right)} \cdot \gamma_{i} \\
& +\underbrace{\theta \cdot \frac{\sigma_{\eta}^{2}\left[\sigma_{\eta}^{2}+\sigma_{\varepsilon}^{2}+\theta^{2}\left(\tilde{\rho}_{i}^{2}+1\right) \sigma_{\gamma}^{2}\right] \cdot \frac{\bar{\tau}-r_{j}}{\bar{\tau}-\tilde{r}_{i}}+\sigma_{\eta}^{2}\left[\sigma_{\varepsilon}^{2}-\theta^{2}\left(\tilde{\rho}_{i}+\tilde{\rho}_{j}\right) \sigma_{\gamma}^{2}\right] \cdot \frac{\bar{\tau}-r_{j}}{\bar{\tau}-\tilde{r}_{j}}}{\left|\Sigma_{22}\right|}}_{a_{5}\left(r_{j}\right)} \cdot \gamma_{j} \\
& +\underbrace{\frac{2 \sigma_{\eta}^{2} \sigma_{\varepsilon}^{2}+\theta^{2}\left\{\left(\tilde{\rho}_{i}+\tilde{\rho}_{j}\right)\left(\tilde{\rho}_{j}-1\right) \sigma_{\eta}^{2}+\left[\left(\tilde{\rho}_{i}+1\right)^{2}+\left(\tilde{\rho}_{j}+1\right)^{2}\right] \sigma_{\varepsilon}^{2}\right\} \sigma_{\gamma}^{2}}{\left|\Sigma_{22}\right|}}_{a_{o}} .
\end{aligned}
$$

With the weights defined as illustrated by the braces, (A.6) reduces to (18).

\section{A.3 Proof of Proposition 1.}

We start by evaluating $\sigma_{i}^{2}\left(r_{1}, r_{2}, \theta\right)=\sigma^{2}(r, r, \theta)$ in $(20)$ at $\tilde{\rho}_{i}=\tilde{\rho}_{j}=1$ and $r_{i}=\tilde{r}_{i}=r_{j}=$ $\tilde{r}_{j}=r$. Doing this gives

$$
\begin{aligned}
\sigma^{2}(r, r, \theta)= & \frac{\sigma_{\eta}^{4}\left(\sigma_{\eta}^{2}+\sigma_{\varepsilon}^{2}+2 \theta^{2} \sigma_{\gamma}^{2}\right)^{2}}{\left|\Sigma_{22}\right|^{2}} \cdot \sigma_{\eta}^{2}+\frac{\sigma_{\eta}^{4}\left(\sigma_{\varepsilon}^{2}-2 \theta^{2} \sigma_{\gamma}^{2}\right)^{2}}{\left|\Sigma_{22}\right|^{2}} \cdot \sigma_{\eta}^{2} \\
& +\frac{\sigma_{\eta}^{4}\left[\left(\sigma_{\eta}^{2}+\sigma_{\varepsilon}^{2}+2 \theta^{2} \sigma_{\gamma}^{2}\right)-\left(\sigma_{\varepsilon}^{2}-2 \theta^{2} \sigma_{\gamma}^{2}\right)\right]^{2}}{\left|\Sigma_{22}\right|^{2}} \cdot \sigma_{\varepsilon}^{2} \\
& +\frac{2 \theta^{2} \sigma_{\eta}^{4}\left[\left(\sigma_{\eta}^{2}+\sigma_{\varepsilon}^{2}+2 \theta^{2} \sigma_{\gamma}^{2}\right)+\left(\sigma_{\varepsilon}^{2}-2 \theta^{2} \sigma_{\gamma}^{2}\right)\right]^{2}}{\left|\Sigma_{22}\right|^{2}} \cdot \sigma_{\gamma}^{2} \\
= & \frac{\sigma_{\eta}^{4}}{\left|\Sigma_{22}\right|^{2}} \cdot\left(\sigma_{\eta}^{2}+\sigma_{\varepsilon}^{2}+2 \theta^{2} \sigma_{\gamma}^{2}\right)\left(\sigma_{\eta}^{2}+2 \sigma_{\varepsilon}^{2}\right)\left(\sigma_{\eta}^{2}+4 \theta^{2} \sigma_{\gamma}^{2}\right) .
\end{aligned}
$$

Taking now the square root of (A.7) and substituting into (29) gives (30). 


\section{A.4 Proof of Proposition 2.}

Differentiating (30) with respect to $t$ gives

$$
\begin{aligned}
r^{\prime}(\theta(t)) \theta^{\prime}(t)= & -\frac{1}{2}\left(\frac{\sigma_{\eta}^{2}+\sigma_{\varepsilon}^{2}+2 \theta^{2} \sigma_{\gamma}^{2}}{\left(\sigma_{\eta}^{2}+2 \sigma_{\varepsilon}^{2}\right)\left(\sigma_{\eta}^{2}+4 \theta^{2} \sigma_{\gamma}^{2}\right) 2 \pi}\right)^{-1 / 2} \\
& \cdot \frac{4 \theta \sigma_{\gamma}^{2}\left(\sigma_{\eta}^{2}+4 \theta^{2} \sigma_{\gamma}^{2}\right)-8 \theta \sigma_{\gamma}^{2}\left(\sigma_{\eta}^{2}+\sigma_{\varepsilon}^{2}+2 \theta^{2} \sigma_{\gamma}^{2}\right)}{2 \pi\left(\sigma_{\eta}^{2}+2 \sigma_{\varepsilon}^{2}\right)\left(\sigma_{\eta}^{2}+4 \theta^{2} \sigma_{\gamma}^{2}\right)^{2}} \cdot \theta^{\prime}(t) \cdot \delta(R+\bar{r}) \cdot(
\end{aligned}
$$

Since $\left\{\left[\sigma_{\eta}^{2}+\sigma_{\varepsilon}^{2}+2 \theta^{2} \sigma_{\gamma}^{2}\right] /\left[\left(\sigma_{\eta}^{2}+2 \sigma_{\varepsilon}^{2}\right)\left(\sigma_{\eta}^{2}+4 \theta^{2} \sigma_{\gamma}^{2}\right) 2 \pi\right]\right\}^{-1 / 2}=\delta(R+\bar{r}) /(\bar{\tau}-r)$, equation (A.8) can be re-written as

$$
\begin{aligned}
r^{\prime}(\theta(t)) \theta^{\prime}(t) & =-\frac{\delta^{2}(R+\bar{r})^{2}}{2(\bar{\tau}-r)} \cdot \frac{4 \theta \sigma_{\gamma}^{2}\left[\sigma_{\eta}^{2}+4 \theta^{2} \sigma_{\gamma}^{2}-2\left(\sigma_{\eta}^{2}+\sigma_{\varepsilon}^{2}+2 \theta^{2} \sigma_{\gamma}^{2}\right)\right]}{2 \pi\left(\sigma_{\eta}^{2}+2 \sigma_{\varepsilon}^{2}\right)\left(\sigma_{\eta}^{2}+4 \theta^{2} \sigma_{\gamma}^{2}\right)^{2}} \cdot \theta^{\prime}(t) \\
& =\frac{\delta^{2}(R+\bar{r})^{2}}{2(\bar{\tau}-r)} \cdot \frac{\theta \sigma_{\gamma}^{2}\left(\sigma_{\eta}^{2}+2 \sigma_{\varepsilon}^{2}\right)}{\pi\left(\sigma_{\eta}^{2}+2 \sigma_{\varepsilon}^{2}\right)\left(\sigma_{\eta}^{2}+2 \theta^{2} \sigma_{\gamma}^{2}\right)^{2}} \cdot \theta^{\prime}(t) \\
& =\frac{\theta \sigma_{\gamma}^{2} \cdot \delta^{2}(R+\bar{r})^{2}}{\pi\left(\sigma_{\eta}^{2}+4 \theta^{2} \sigma_{\gamma}^{2}\right)^{2}(\bar{\tau}-r)} \cdot \theta^{\prime}(t)
\end{aligned}
$$

For $\theta>0$ and with, following $(7), \theta^{\prime}(t)>0,($ A.9) is strictly positive. 


\section{References}

Baretti, C., B. Huber, and K. Lichtblau (2002), A tax on tax revenue: The incentive effects of equalizing transfers: Evidence from Germany, International Tax and Public Finance 9, 631-649.

Belleflamme, P., and J. Hindriks (2005), Yardstick competition and political agency problems, Social Choice and Welfare 24, 155-169.

Besley, T., and A. CAse (1995), Incumbent behavior: Vote-seeking, tax setting, and yardstick competition, American Economic Review 85, 25-45.

Besley, T., and M. Smart (2003), Fiscal restraints and voter welfare, revised version of CEPR Discussion Paper No. 3131.

BOADWAY, R. (1998), The economics of equalization: An overview, in Equalization: Its contribution to Canada's economic and fiscal progress, ed. R. BOADWAY and P. HoBson (Kingston: John Duetsch Institute), 27-82.

BOADWAY, R. (2004), How well is the equalization system reducing fiscal disparities?, mimeo, Queen's University.

Boarnet, M., and A. Glazer (2002), Federal grants and yardstick competition, Journal of Urban Economics 52, 53-64.

Bordignon, M., F. Cerniglia, and F. Revelli (2004), Yardstick competition in intergovernmental relationships: Theory and empirical predictions, Economics Letters 83, 325-333.

Bucovetsky, S., and M. Smart (2006), The efficiency consequences of local revenue equalization: Tax competition and tax distortions, Journal of Public Economic Theory 8, 119-144.

BütTneR, T. (2006), The incentive effect of fiscal equalization transfers on tax policy, Journal of Public Economics 90, 477-497.

Careaga, M., and B. Weingast (2003), Fiscal federalism, good governance, and economic growth in Mexico, in In search of prosperity: analytical narratives on economic growth, ed. D. RoDRIK (Priceton: Priceton University Press), 399-435.

DAhlBy, B. and N. WARREN (2003), The fiscal incentive effects of the Australian equalization system, Economic Record 79, 434-445.

DeGroot, M. (1970), Optimal statistical decisions (New York: McGraw-Hill).

HiNDRIKS, J., and B. LoCKWOOD (2005), Decentralization and electoral accountability: incentives, separation, and voter welfare, mimeo, University of Warwick.

Inman, R. (1998), Federal assistance and local services in the United States: The evolution of a new federalist fiscal order, in Fiscal federalism, ed. H. Rosen (Chicago: University of Chicago Press).

Johansson, E. (2003), Intergovernmental grants as a tactical instrument: Empirical evidence from Swedish municipalities, Journal of Public Economics 87, 883-915.

Karkalakos, S., and C. Kotsogiannis (2006), A spatial analysis of provincial corporate income tax responses: Evidence from Canada, mimeo, University of Exeter. 
Köthenbürger, M. (2002), Tax competition and fiscal equalization, International Tax and Public Finance 9, 391-408.

Lockwood, B. (1999), Inter-regional insurance, Journal of Public Economics 72, 1-37.

Lockwood, B. (2002), Distributive politics and the costs of centralization, Review of Economic Studies 69, 313-337.

OAtes, W. (2005), Towards a second-generation theory of fiscal federalism, International Tax and Public Finance 12, 349-373.

Persson T., and G. Tabellini (2000), Political economics: Explaining economic policy (Cambridge: The MIT Press).

RevelLi, F. (2006), Performance rating and yardstick competition in social service provision, Journal of Public Economics 90, 459-475.

Seabright, P. (1996), Accountability and decentralization in government: An incomplete contracts model, European Economic Review 40, 61-91.

Smart, M. (1998), Taxation and deadweight loss in a system of intergovernmental transfers, Canadian Journal of Economics 31, 189-206.

Smart, M. (2005), Some notes on equalization reform, mimeo, University of Toronto.

Weingast, B. (2006), Second generation fiscal federalism: Implications for decentralized democratic governance and economic development, discussion draft paper presented at the IFIR/CESIfo Conference on 'New Direction in Fiscal Federalism', Lexington, Kentucky, September 14th-16th, 2006.

WiLDASIn, D. (1989), Interjurisdictional capital mobility: Fiscal externality and a corrective subsidy, Journal of Urban Economics 25, 193-212. 


\title{
CESifo Working Paper Series
}

\author{
(for full list see www.cesifo-group.de)
}

1804 David-Jan Jansen and Jakob de Haan, Does ECB Communication Help in Predicting its Interest Rate Decisions?, September 2006

1805 Jerome L. Stein, United States Current Account Deficits: A Stochastic Optimal Control Analysis, September 2006

1806 Friedrich Schneider, Shadow Economies and Corruption all over the World: What do we really Know?, September 2006

1807 Joerg Lingens and Klaus Waelde, Pareto-Improving Unemployment Policies, September 2006

1808 Axel Dreher, Jan-Egbert Sturm and James Raymond Vreeland, Does Membership on the UN Security Council Influence IMF Decisions? Evidence from Panel Data, September 2006

1809 Prabir De, Regional Trade in Northeast Asia: Why do Trade Costs Matter?, September 2006

1810 Antonis Adam and Thomas Moutos, A Politico-Economic Analysis of Minimum Wages and Wage Subsidies, September 2006

1811 Guglielmo Maria Caporale and Christoph Hanck, Cointegration Tests of PPP: Do they also Exhibit Erratic Behaviour?, September 2006

1812 Robert S. Chirinko and Hisham Foad, Noise vs. News in Equity Returns, September 2006

1813 Oliver Huelsewig, Eric Mayer and Timo Wollmershaeuser, Bank Behavior and the Cost Channel of Monetary Transmission, September 2006

1814 Michael S. Michael, Are Migration Policies that Induce Skilled (Unskilled) Migration Beneficial (Harmful) for the Host Country?, September 2006

1815 Eytan Sheshinski, Optimum Commodity Taxation in Pooling Equilibria, October 2006

1816 Gottfried Haber and Reinhard Neck, Sustainability of Austrian Public Debt: A Political Economy Perspective, October 2006

1817 Thiess Buettner, Michael Overesch, Ulrich Schreiber and Georg Wamser, The Impact of Thin-Capitalization Rules on Multinationals' Financing and Investment Decisions, October 2006

1818 Eric O’N. Fisher and Sharon L. May, Relativity in Trade Theory: Towards a Solution to the Mystery of Missing Trade, October 2006 
1819 Junichi Minagawa and Thorsten Upmann, Labor Supply and the Demand for Child Care: An Intertemporal Approach, October 2006

1820 Jan K. Brueckner and Raquel Girvin, Airport Noise Regulation, Airline Service Quality, and Social Welfare, October 2006

1821 Sijbren Cnossen, Alcohol Taxation and Regulation in the European Union, October 2006

1822 Frederick van der Ploeg, Sustainable Social Spending in a Greying Economy with Stagnant Public Services: Baumol’s Cost Disease Revisited, October 2006

1823 Steven Brakman, Harry Garretsen and Charles van Marrewijk, Cross-Border Mergers \& Acquisitions: The Facts as a Guide for International Economics, October 2006

1824 J. Atsu Amegashie, A Psychological Game with Interdependent Preference Types, October 2006

1825 Kurt R. Brekke, Ingrid Koenigbauer and Odd Rune Straume, Reference Pricing of Pharmaceuticals, October 2006

1826 Sean Holly, M. Hashem Pesaran and Takashi Yamagata, A Spatio-Temporal Model of House Prices in the US, October 2006

1827 Margarita Katsimi and Thomas Moutos, Inequality and the US Import Demand Function, October 2006

1828 Eytan Sheshinski, Longevity and Aggregate Savings, October 2006

1829 Momi Dahan and Udi Nisan, Low Take-up Rates: The Role of Information, October 2006

1830 Dieter Urban, Multilateral Investment Agreement in a Political Equilibrium, October 2006

1831 Jan Bouckaert and Hans Degryse, Opt In Versus Opt Out: A Free-Entry Analysis of Privacy Policies, October 2006

1832 Wolfram F. Richter, Taxing Human Capital Efficiently: The Double Dividend of Taxing Non-qualified Labour more Heavily than Qualified Labour, October 2006

1833 Alberto Chong and Mark Gradstein, Who's Afraid of Foreign Aid? The Donors' Perspective, October 2006

1834 Dirk Schindler, Optimal Income Taxation with a Risky Asset - The Triple Income Tax, October 2006

1835 Andy Snell and Jonathan P. Thomas, Labour Contracts, Equal Treatment and WageUnemployment Dynamics, October 2006 
1836 Peter Backé and Cezary Wójcik, Catching-up and Credit Booms in Central and Eastern European EU Member States and Acceding Countries: An Interpretation within the New Neoclassical Synthesis Framework, October 2006

1837 Lars P. Feld, Justina A.V. Fischer and Gebhard Kirchgaessner, The Effect of Direct Democracy on Income Redistribution: Evidence for Switzerland, October 2006

1838 Michael Rauscher, Voluntary Emission Reductions, Social Rewards, and Environmental Policy, November 2006

1839 Vincent Vicard, Trade, Conflicts, and Political Integration: the Regional Interplays, November 2006

1840 Erkki Koskela and Mikko Puhakka, Stability and Dynamics in an Overlapping Generations Economy under Flexible Wage Negotiation and Capital Accumulation, November 2006

1841 Thiess Buettner, Michael Overesch, Ulrich Schreiber and Georg Wamser, Taxation and Capital Structure Choice - Evidence from a Panel of German Multinationals, November 2006

1842 Guglielmo Maria Caporale and Alexandros Kontonikas, The Euro and Inflation Uncertainty in the European Monetary Union, November 2006

1843 Jan K. Brueckner and Ann G. Largey, Social Interaction and Urban Sprawl, November 2006

1844 Eytan Sheshinski, Differentiated Annuities in a Pooling Equilibrium, November 2006

1845 Marc Suhrcke and Dieter Urban, Are Cardiovascular Diseases Bad for Economic Growth?, November 2006

1846 Sam Bucovetsky and Andreas Haufler, Preferential Tax Regimes with Asymmetric Countries, November 2006

1847 Luca Anderlini, Leonardo Felli and Andrew Postlewaite, Should Courts always Enforce what Contracting Parties Write?, November 2006

1848 Katharina Sailer, Searching the eBay Marketplace, November 2006

1849 Paul De Grauwe and Pablo Rovira Kaltwasser, A Behavioral Finance Model of the Exchange Rate with Many Forecasting Rules, November 2006

1850 Doina Maria Radulescu and Michael Stimmelmayr, ACE vs. CBIT: Which is Better for Investment and Welfare?, November 2006

1851 Guglielmo Maria Caporale and Mario Cerrato, Black Market and Official Exchange Rates: Long-Run Equilibrium and Short-Run Dynamics, November 2006 
1852 Luca Anderlini, Leonardo Felli and Andrew Postlewaite, Active Courts and Menu Contracts, November 2006

1853 Andreas Haufler, Alexander Klemm and Guttorm Schjelderup, Economic Integration and Redistributive Taxation: A Simple Model with Ambiguous Results, November 2006

1854 S. Brock Blomberg, Thomas DeLeire and Gregory D. Hess, The (After) Life-Cycle Theory of Religious Contributions, November 2006

1855 Albert Solé-Ollé and Pilar Sorribas-Navarro, The Effects of Partisan Alignment on the Allocation of Intergovernmental Transfers. Differences-in-Differences Estimates for Spain, November 2006

1856 Biswa N. Bhattacharyay, Understanding the Latest Wave and Future Shape of Regional Trade and Cooperation Agreements in Asia, November 2006

1857 Matz Dahlberg, Eva Mörk, Jørn Rattsø and Hanna Ågren, Using a Discontinuous Grant to Identify the Effect of Grants on Local Taxes and Spending, November 2006

1858 Ernesto Crivelli and Klaas Staal, Size and Soft Budget Constraints, November 2006

1859 Jens Brøchner, Jesper Jensen, Patrik Svensson and Peter Birch Sørensen, The Dilemmas of Tax Coordination in the Enlarged European Union, November 2006

1860 Marcel Gérard, Reforming the Taxation of Multijurisdictional Enterprises in Europe, "Coopetition” in a Bottom-up Federation, November 2006

1861 Frank Blasch and Alfons J. Weichenrieder, When Taxation Changes the Course of the Year - Fiscal Year Adjustments and the German Tax Reform 2000/2001, November 2006

1862 Hans Jarle Kind, Tore Nilssen and Lars Sørgard, Competition for Viewers and Advertisers in a TV Oligopoly, November 2006

1863 Bart Cockx, Stéphane Robin and Christian Goebel, Income Support Policies for PartTime Workers: A Stepping-Stone to Regular Jobs? An Application to Young LongTerm Unemployed Women in Belgium, December 2006

1864 Sascha O. Becker and Marc-Andreas Muendler, The Effect of FDI on Job Separation, December 2006

1865 Christos Kotsogiannis and Robert Schwager, Fiscal Equalization and Yardstick Competition, December 2006 